\title{
Measurement of atomic oxygen in the middle atmosphere using solid electrolyte sensors and catalytic probes
}

\author{
M. Eberhart ${ }^{1}$, S. Löhle ${ }^{1}$, A. Steinbeck ${ }^{2}$, T. Binder ${ }^{1}$, and S. Fasoulas ${ }^{1}$ \\ ${ }^{1}$ Institute of Space Systems, University of Stuttgart, Stuttgart, Germany \\ ${ }^{2}$ Airbus DS GmbH, Lampoldshausen, Germany \\ Correspondence to: M. Eberhart (eberhart@irs.uni-stuttgart.de)
}

Received: 26 January 2015 - Published in Atmos. Meas. Tech. Discuss.: 24 March 2015

Revised: 25 June 2015 - Accepted: 10 August 2015 - Published: 15 September 2015

\begin{abstract}
The middle- and upper-atmospheric energy budget is largely dominated by reactions involving atomic oxygen (O). Modeling of these processes requires detailed knowledge about the distribution of this oxygen species. Understanding the mutual contributions of atomic oxygen and wave motions to the atmospheric heating is the main goal of the rocket project WADIS (WAve propagation and DISsipation in the middle atmosphere). It includes, amongst others, our instruments for the measurement of atomic oxygen that have both been developed with the aim of resolving density variations on small vertical scales along the trajectory. In this paper the instrument based on catalytic effects (PHLUX: Pyrometric Heat Flux Experiment) is introduced briefly. The experiment employing solid electrolyte sensors (FIPEX: Flux $\phi(\mathrm{Phi})$ Probe Experiment) is presented in detail. These sensors were laboratory calibrated using a microwave plasma as a source of atomic oxygen in combination with mass spectrometer reference measurements. The spectrometer was in turn calibrated for $\mathrm{O}$ with a method based on methane. In order to get insight into the horizontal variability, the rocket payload had instrument decks at both ends. Each housed several sensor heads measuring during both the up- and downleg of the trajectory. The WADIS project comprises two rocket flights during different geophysical conditions. Results from WADIS- 1 are presented, which was successfully launched in June 2013 from the Andøya Space Center, Norway. FIPEX data were sampled at $100 \mathrm{~Hz}$ and yield atomic oxygen density profiles with a vertical resolution better than $9 \mathrm{~m}$. This allows density variations to be studied on very small spatial scales. Numerical simulations of the flow field around the rocket were done at several points of the trajectory to assess the influence of aerodynamic effects on the measurement re-
\end{abstract}

sults. Density profiles peak at $3 \times 10^{10} \mathrm{~cm}^{-3}$ at altitudes of 93.6 and $96 \mathrm{~km}$ for the up- and downleg, respectively.

\section{Introduction}

Atomic oxygen (O) is a highly reactive species and a key element in a number of atmospheric processes. At high altitudes it is one of the major constituents of Earth's atmosphere and may cause erosion to exposed parts of spacecraft, especially on solar panels of satellites and the International Space Station (Reddy, 1995). In the mesosphere and lower thermosphere (MLT) $\mathrm{O}$ is an important carrier of chemical energy and plays a significant role in the distribution of solar energy (e.g., Hedin et al., 2009). Atomic oxygen is produced by photodissociation of $\mathrm{O}_{2}$ and is then dispersed via various processes such as turbulent mixing. The chemical energy stored is released upon recombination, and as the lifetime of the radicals is long in the upper regions the heating may occur at a large distance from the source, horizontally as well as vertically. On the other hand, atomic oxygen is also involved in the most important heat sink in the MLT, the radiation of $\mathrm{CO}_{2}$ in the $15 \mu \mathrm{m}$ band, where the population of the relevant energy levels depends mainly on collisions with O (e.g., Mlynczak, 1996). Determination of local atomic oxygen densities is therefore a necessity for detailed modeling of the atmospheric energy budget and understanding of the underlying physical processes. The demand for high spatial resolution requires in situ measurement techniques, and the altitudes of interest leave sounding rockets as the only appropriate instrument carriers. In the past decades numerous experiments with a number of different measure- 
ment techniques have been flown on sounding rockets to retrieve profiles of atomic oxygen number densities. A method that is known to be very accurate is the use of cryogenic mass spectrometers where the shock front of the payload is "frozen out", which minimizes the influence of the aerodynamics (e.g., Offermann et al., 1981). This accuracy comes at the cost of a very high system complexity. Several optical techniques have been used for in situ measurements on rockets that probe emission, absorption or fluorescence of atomic oxygen or species that are linked to it by a known reaction chain. Measurement of the so-called airglow is a method with a rather low instrumental complexity which determines the intensity of natural emissions involving $\mathrm{O}$ reactions at various wavelengths (e.g., Offermann and Drescher, 1973). This technique basically requires only photometers and appropriate filters. A key factor is the exact knowledge of the rate constants associated with the relevant reactions. A method with good sensitivity and selectivity uses resonant fluorescence of atomic oxygen in the vacuum ultraviolet (VUV) at $130 \mathrm{~nm}$. The emission from a lamp is absorbed by $\mathrm{O}$ atoms, and the resonantly scattered photons are collected by a photomultiplier (e.g., Thomas and Young, 1981). This instrument can be complemented with absorption measurements at the same wavelength (e.g., Gumbel et al., 1998). Improvements on the accuracy could be made by using $\mathrm{O}_{2}$ airglow measurements, carried out simultaneously, for calibration of the resonant fluorescence analysis (Hedin et al., 2009). A review of techniques for the determination of atomic oxygen densities aboard sounding rockets and satellites can be found in Osborne et al. (2001). In order to quantify the contribution both of dissipating gravity waves and of atomic oxygen to the atmospheric heating, the project WADIS (WAve propagation and DISsipation in the middle atmosphere) has been set up (Gritzner and Rapp, 2011; Gritzner and Strelnikov, 2013). The project is led by the Leibniz Institute of Atmospheric Physics (IAP) under a grant from the German Aerospace Center (DLR). Several institutions provided rocket-borne experiments for the direct measurement of small-scale turbulences and various neutral and charged particles in combination with ground-based observations using radar and lidar. The project foresees two launches of sounding rockets in very different geophysical conditions, during winter- and summertime. The Institute of Space Systems (IRS) has contributed to this project with the development of two new sensor systems designed for the determination of atomic oxygen density profiles along the trajectory. The first instrument, called FIPEX (Flux $\phi(\mathrm{Phi})$ Probe Experiment), is based on solid electrolyte sensors, a technique that has been successfully flown on a number of rocket missions. On TEXUS 34 (Technologische Experimente unter Schwerelosigkeit, 1996) a modified commercial lambda probe was employed to measure $\mathrm{O}_{2}$ densities (Schrempp, 1996), followed by miniaturized sensors on the Russian capsules IRDT (Inflatable Reentry and Descent Technology, 2000) and IRDT-2 (Fasoulas et al., 2001). The sensors used in these campaigns, however, could not distinguish between molecular and atomic oxygen. A refined version with improved selectivity towards $\mathrm{O}$ was used in an experiment on the International Space Station (2008) (Schmiel, 2009). WADIS is the first project to employ this measurement principle for the determination of atomic oxygen densities aboard a sounding rocket. The sensors are very small in size, are lightweight, have low power consumption and feature a high temporal and therefore spatial resolution. The second sensor system, named PHLUX (Pyrometric Heat Flux Experiment), measures temperature on two surfaces with different catalytic activities towards the recombination of atomic oxygen. The surface that promotes recombination receives a higher amount of chemical heat, leading to a temperature difference between the surfaces proportional to the incident atomic oxygen flux. Such catalytic probes have previously been used for atmospheric research on sounding rockets, albeit with a different design (Perov and Rakhmanov, 1977). We adopted a concept originally developed for ESA's re-entry capsule EXPERT (European eXPErimental Reentry Testbed) (Herdrich et al., 2005). The basic idea was to simultaneously operate two measurement systems based on different principles and yet very similar in overall size and position on the rocket. The first sounding rocket of the WADIS project was launched on 27 June 2013 at the Andøya Space Center in Andenes, Norway, at 23:52 h UTC. The payload had two instrument decks, one fore and one aft. They were symmetrically equipped with FIPEX and PHLUX sensors, together with several other experiments: CONE (COmbined measurement of Neutrals and Electrons): neutral and electron density, temperature, IAP (Rapp et al., 2001); particle detector, IAP; positive ion probe (PIP), TU Graz; Faraday antenna: electron density, TU Graz (Friedrich et al., 2013); two photometers, one measuring in the $\mathrm{O}_{2}$ IR A band at $1270 \mathrm{~nm}$ (atomic oxygen, ozone) and one at $220 \mathrm{~nm}$ (noctilucent clouds (NLC)), both photometers from MISU Stockholm (e.g., Hedin et al., 2009, 2008); and a new fixed-bias Langmuir probe comprising surfaces with different work functions: electron density, Embry-Riddle. The payload had a constant, almost vertical orientation during the experimentation phase, and the instrumentation of the rocket on both ends had the benefit of measurements during both the up- and downleg of the trajectory, which enables conclusions about the horizontal distribution of relevant parameters. An apogee of $115 \mathrm{~km}$ was reached, $5 \mathrm{~km}$ short of the planned trajectory. In this paper we present the applied measuring principles of the two IRS sensor systems. FIPEX data and the derived atomic oxygen density profiles will be discussed and compared to literature values. Details about the PHLUX operation and its results will be published in a companion paper. 


\section{Solid electrolyte sensor FIPEX}

The so-called lambda-probe presents the most prominent example of a solid electrolyte oxygen sensor. It measures the oxygen concentration in automobile exhaust gases in order to regulate the motor's air/fuel ratio. This sensor type is based on a ceramic solid electrolyte, often yttria stabilized zirconia (YSZ). Due to the structure of its crystal lattice it is a conductor for oxygen anions, $\mathrm{O}^{2-}$. If a suitable interface is provided, gas phase oxygen may be built into this lattice. This is accomplished by applying an electronically conductive platinum electrode onto the electrolyte surface. Here a multi-step reaction occurs (e.g., Hertz, 2006, p. 24): gaseous $\mathrm{O}_{2}$ is transported to the electrodes by bulk diffusion; it is adsorbed dissociatively on the surface; the $\mathrm{O}$ atoms are then driven to electrochemically active sites by surface diffusion; here oxygen is reduced in a charge transfer step to $\mathrm{O}^{2-}$ by electrons delivered by the electrode; and the ions are then built into vacant lattice sites of the electrolyte structure. The active sites are essentially found on the so-called triple-phase boundary where electrode, electrolyte and gas phase are in direct contact. As electrons are moved in the charge transfer reaction, the electrical potential of the electrode changes until an equilibrium is reached. The steady-state potential depends on the gas phase oxygen concentration. The potential difference $\Delta \Phi$ between two electrodes facing unequal gas compositions is given by the Nernst equation (e.g., Oldham and Myland, 1994):

$\Delta \Phi=\frac{R T}{n F} \ln \frac{c_{1}}{c_{2}}$.

$R$ is the universal gas constant, $T$ the absolute temperature, $F$ Faraday's constant and $n$ the number of electrons involved in the reaction. The oxygen concentrations above two electrodes in different environments are given by $c_{1}$ and $c_{2}$. If one electrode is exposed to a defined reference atmosphere, then the oxygen concentration on the other side can be determined by measuring the steady-state value of $\Delta \Phi$. Such a sensor works according to the so-called potentiometric principle.

If an external voltage $U_{S}$ is applied to the electrodes, superposing the Nernst potential, the system is forced out of equilibrium and oxygen ions are driven through the electrolyte from cathode to anode. This results in a net flow that is associated with an electrical current $I_{S}$ measurable at the electrodes. So-called amperometric sensors make use of this principle and show a wide measurement range over several orders of magnitude of oxygen partial pressure. The net flow of oxygen ions persists if both electrodes are brought to the same environment. Without the requirement of a reference atmosphere these sensors can be designed with a compact planar layout. Commonly a third electrode is employed as a reference and the voltage $U_{S}$ regulated such that the potential difference between cathode and reference is a constant value. The benefit of this is a linear dependence of the measured sensor current on oxygen pressure over a wide range.

An important factor for the sensor behavior is the electrode material. Besides being a good electronic conductor and being both thermally and chemically stable, it has to promote the dissociative adsorption of molecular oxygen. As stated before, platinum exhibits all these features (Schwandt and Weppner, 1997).

By contrast, $\mathrm{O}_{2}$ is not adsorbed on gold surfaces under high vacuum conditions, except in the case of impurities, e.g., silicon or calcium (Légaré et al., 1980; Pireaux et al., 1984), so that a sensor with gold electrodes responds to molecular oxygen to a much lesser degree. However, gas phase atomic oxygen is adsorbed directly here and may readily be incorporated into the described reaction chain. This provides the possibility of designing sensors with a selective response to atomic oxygen by using gold cathodes.

All the reaction mechanisms on the electrodes and in the electrolyte are temperature dependent. In particular the ion conductivity of YSZ rises exponentially with temperature (Park and Blumenthal, 1989) and requires the sensor to be heated to about $500{ }^{\circ} \mathrm{C}$. It should be noted that the sensor currents for both molecular and atomic types are proportional to the flux of particles onto their surfaces and therefore respond to the total pressure if exposed to a moving medium.

The design of the amperometric sensor elements used in this paper is shown in Fig. 1. A functional YSZ film was screen printed from a paste (Tosoh Corporation, Japan) onto an alumina substrate. Two electrodes with an interdigitated layout and a third reference electrode were screen printed on top of the YSZ layer. A resistance heater was applied to the back side of the alumina plate, again by means of screen printing. Platinum paste (Ferro 64120410, Germany) was used for both the electrodes and the heater; for the electrodes the paste was mixed with YSZ powder (Tosoh Corporation, Japan), giving a porous layer with an increased triple-phase boundary. Electrodes and the heater were contacted with gap-welded Pt-Ni leads. In order to obtain sensors selectively sensitive to atomic oxygen, the cathode was subsequently electroplated with gold. This was achieved by placing the sensors in an electrolyte solution (no. 530522, Dr. Ropertz GmbH, Germany), with a voltage of $3.0 \mathrm{~V}$ applied between cathode and a stainless-steel counter electrode for $3 \mathrm{~min}$ at a current of $10 \mathrm{~mA}$. The electrical circuit used to control and read out the sensors is shown in Fig. 2. A controller stabilizes the potential between cathode and reference to $300 \mathrm{mV}$ by adjusting the $U_{S}$ voltage. The sensor signal is the current $I_{S}$ measured between anode and cathode. The sensor element is kept at a constant temperature throughout the flight by regulating the resistance heater to a defined ohmic value. Two sensors are mounted together in a common aluminum housing, one with a golden and one with a platinum cathode, as shown in Fig. 3. The platinum sensor is sensitive to both molecular and atomic oxygen, while the gold sensor selectively measures the $\mathrm{O}$ density. Two heat- 


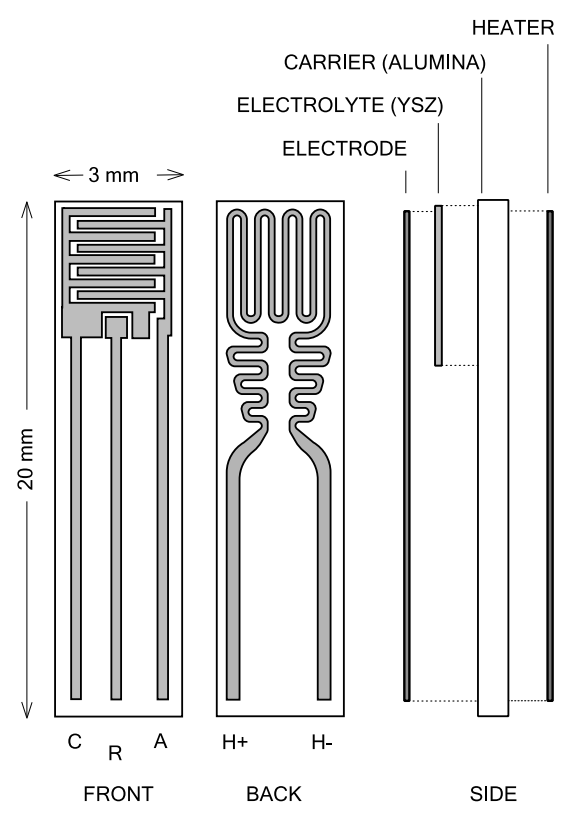

Figure 1. Layout of a FIPEX sensor. Electrodes are made of platinum; for atomic oxygen sensors the cathode is additionally gold coated.

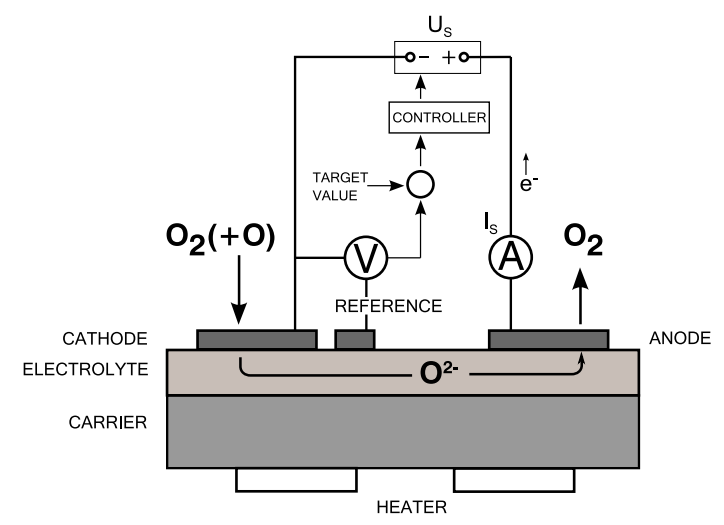

Figure 2. Electrical circuit of a sensor with three-electrode design and regulation of the reference voltage.

resistant ceramic elements hold the sensors in place, and the leads are soldered to a LEMO connector.

This ensemble with two different sensors makes up a sensor head; to ensure redundancy three of these heads were mounted on both the fore and aft deck of the payload. The sensors were operated by custom designed electronics, one on each deck, connected to the heads by a thoroughly shielded cable. The sampling frequency of the sensor data was $100 \mathrm{~Hz}$. Considering the rocket speed along the trajectory, this results in a theoretical vertical resolution better than $9 \mathrm{~m}$ during the flight. The photograph given in Fig. 4 shows the final assembly of the instruments on the fore deck of the rocket, with both a FIPEX and PHLUX sensor head visible. Pairs of heads were distributed with a $120^{\circ}$ spacing on an

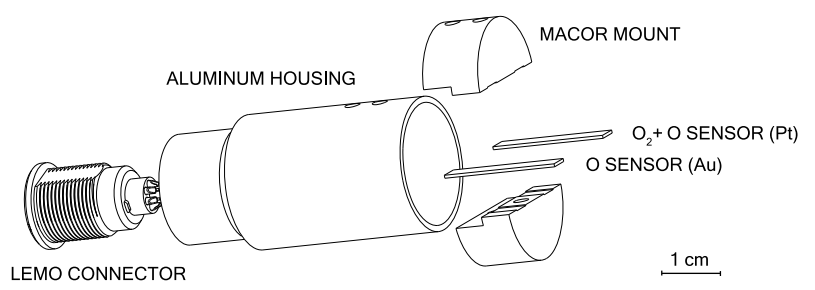

Figure 3. FIPEX head with two sensors $\left(\mathrm{O}\right.$ and $\left.\mathrm{O}+\mathrm{O}_{2}\right)$ mounted in a common housing.

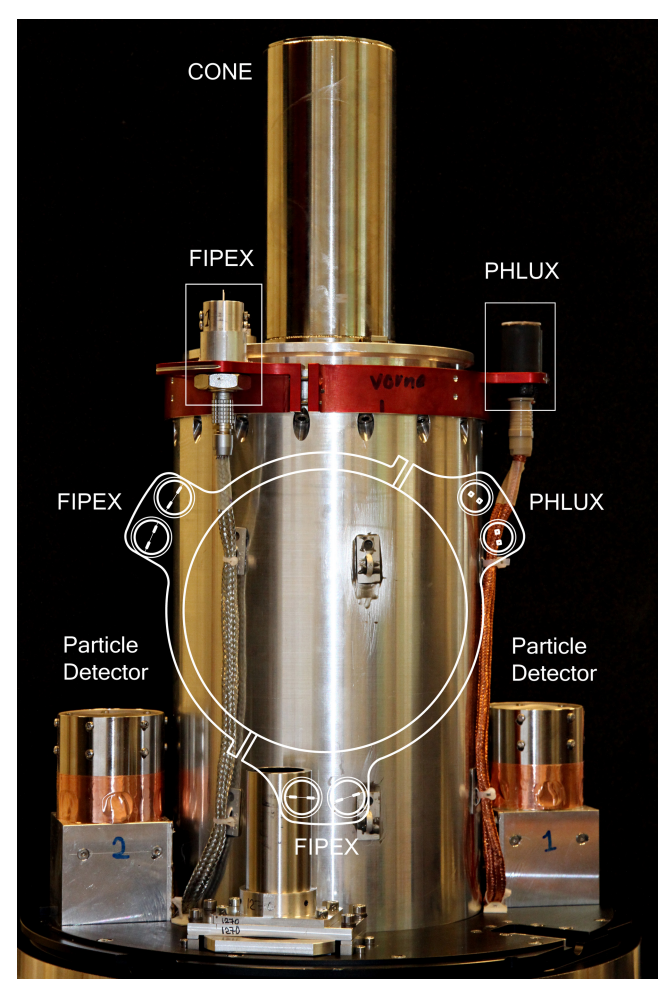

Figure 4. Payload on the fore deck of the rocket with both a FIPEX and PHLUX sensor head visible and a sketch showing their arrangement. Other instruments in the photo are the particle detectors and the CONE ionization gauge, all from IAP. CONE is covered by an evacuated hood.

adapter ring. The FIPEX sensors were mounted parallel to the rocket axis so that their sensitive electrode surface is oriented perpendicular to the main component of the flight velocity. This orientation was chosen to minimize the influence of the rocket speed on the measured oxygen flux.

\section{Catalytic Probe PHLUX}

Two oxygen atoms recombining on a surface release an energy of $5.2 \mathrm{eV}$ (Hammer et al., 1999), leading to a temperature increase. The number of recombinations in a time interval depends on the flux of atoms onto the surface and on its catalytic activity towards this reaction, expressed by a re- 
combination coefficient $\gamma$. The heat flux can be related to the incident chemical heat and thus to the atomic oxygen density. To account for varying and unknown heat transfer coefficients from the surface to the surroundings, a second inert probe is used. Its heat flux variations reflect all other heat transfer mechanisms, like convection and radiation. In the PHLUX probe head two Pt100 temperature sensors (Heraeus type L220P, sensor area $2 \times 2 \mathrm{~mm}$ ) with different coatings, silicon dioxide $\left(\mathrm{SiO}_{2}\right)$ and platinum, have been placed close to each other. Platinum is a highly catalytic material, while $\mathrm{SiO}_{2}$ is used as an inert reference with $\gamma$ close to zero. In order to minimize heat losses to the structure, the Pt100 elements are embedded in an aerogel pad (Airloy from Aerogel Technologies Inc., USA) with extremely low thermal conduction. To account for heat losses through the sensor lead wires, the temperature of the connector pins is measured by a thermocouple. Figure 5 shows the complete sensor head with a PEEK housing. Similar to FIPEX two heads are mounted on each payload deck for the sake of redundancy. According to the original schedule WADIS-1 was planned in wintertime, in dim light or during night. Sunlight became an obstacle to the PHLUX measurements as plans had to be shifted to summer conditions. Solar radiative heat exceeds the chemical contributions on both the coated and the uncoated surface. As the absorption coefficients and their dependence on wavelength and temperature are not known exactly, the concept was altered to rule out this source of error. One of the sensor heads was covered with a sapphire window, so that the surfaces beneath do not receive any chemical heat and the temperatures represent the pure solar contributions. These values can be subtracted from the results of the uncovered head, leaving the effect from atomic recombination if convection is assumed to be identical on both heads. This step was omitted on the aft deck as no direct sunlight was expected here. Custom electronics were used to read the temperature of the thermocouples and the resistance of the Pt100 elements. Fourwire measurement eliminated uncertainties due to different cable lengths. Sensor data were sampled with a frequency of $1000 \mathrm{~Hz}$.

\section{Calibration}

As no first-principles model can be employed for the interpretation of the sensor readings, a laboratory calibration is necessary. This applies especially to solid electrolyte sensors, for both molecular and atomic oxygen, but more generally also to the catalytic probes. Here parameters like the catalytic efficiencies, absorption and emission coefficients or other thermo-physical properties of the sensor design are only known with high uncertainties. In the following the calibration method for the FIPEX sensors is detailed. The PHLUX sensors were calibrated for the incident heat flux density using the NISI (non-integer system identification) method (Löhle et al., 2013, 2007).

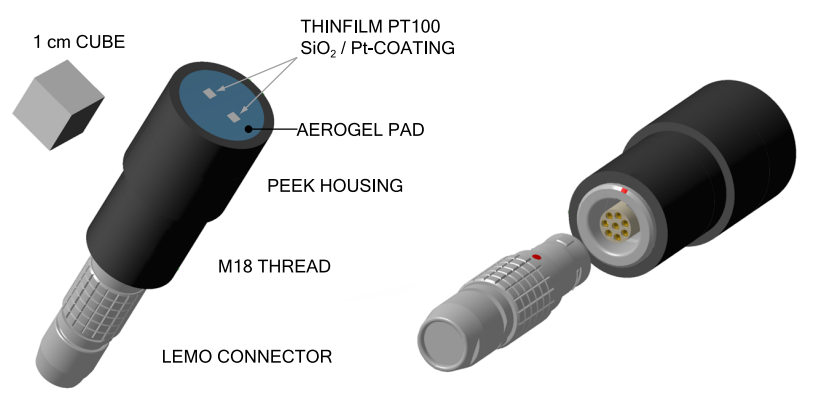

Figure 5. Design of the PHLUX sensor head.

A microwave generator $(2.45 \mathrm{GHz}$, Sairem, France) is used to produce a low-pressure oxygen plasma as a source of atomic oxygen, a technique widely employed in various technical and scientific applications and well studied in the literature (Lebedev, 2010). The pure-oxygen plasma is sustained within a cylindrical quartz tube at an oxygen pressure of $1.0 \mathrm{mbar}$ and an incident microwave power of up to $300 \mathrm{~W}$. The tube has a length of $30 \mathrm{~cm}$ with an outer diameter of $50 \mathrm{~mm}$ and a wall thickness of $2.5 \mathrm{~mm}$ and is mounted onto a vacuum chamber. The atomic oxygen generated in the discharge is expanded into the vacuum through a small orifice $(\varnothing 0.3 \mathrm{~mm})$ along with undissociated molecular oxygen. This generates a fast beam with a distinct radial and axial distribution of the atomic oxygen density. In a first step the radial profile of the degree of dissociation in this beam is determined with a quadrupole mass spectrometer (QMS, Hiden HAL 3F with cross-beam ion source). The QMS is mounted on a flexible bellow with its axis perpendicular to the beam. A mechanism allows variation of the radial position of the QMS, thus recording the desired profile. The degree of dissociation is obtained as the ratio between the readings at mass numbers $16(\mathrm{O})$ and $32\left(\mathrm{O}_{2}\right)$. To suppress dissociative products in the ion source, which corrupt the measurement, a low electron energy of $16 \mathrm{eV}$ is used. As the QMS is operated with non-standard parameters, it in turn has to be calibrated. For this purpose we employ a method involving methane $\left(\mathrm{CH}_{4}\right)$ that shares mass number 16 with atomic oxygen (Agarwal et al., 2004). The energy scale of the ionizer is calibrated against the well-know appearance potential of argon. It should be stressed that the mass spectrometer only determines static number densities regardless of the velocity of the medium (Singh et al., 2000). However, the calibration of the sensors requires knowledge of the flux of $\mathrm{O}$ atoms in the beam. Therefore a second measurement is required to provide the total flux, which can be combined with the degree of dissociation to form the profile of atomic oxygen total pressure needed for calibration. This measurement is made in the pure- $\mathrm{O}_{2}$ beam (plasma off) with a solid electrolyte sensor with platinum electrodes calibrated for $\mathrm{O}_{2}$ under static conditions. As the beam profile is radially symmetric, this sensor is mounted on a linear/rotary manipulator (MDC BRLM-275) opposing the QMS, together with the 
atomic oxygen sensor to be calibrated. After the total flux profile has been determined the manipulator is turned about $180^{\circ}$, so that the second sensor is exposed to the beam and its response to the radially varying atomic flux (plasma on) can be recorded. This enables an almost simultaneous operation of the $\mathrm{O}$ sensor and the QMS reference system without the need of opening the vacuum chamber between measurements. Calibration curves for atomic oxygen obtained by this procedure are given in Fig. 6 for the sensors used during WADIS-1. The different slopes of the curves are due to tolerances in the manufacturing of the sensors. Slight variations in the heater geometry and the position of the electrodes on the substrate, for example, lead to temperature differences that directly affect the sensor signal. Variations in the spacing between the electrodes furthermore result in a differing conductance across the electrolyte.

Calibration for molecular oxygen is done by testing the sensors in a vacuum chamber under stationary conditions. The partial pressure of $\mathrm{O}_{2}$ is varied by a leak valve (Balzers UDV 235), and the sensor current is measured against a pressure gauge (Pfeiffer FullRange PKR251). Results for one sensor (C24) with platinum cathodes are plotted exemplarily in Fig. 7. Values for the gold-plated atomic oxygen sensor $\mathrm{C} 15$ are given additionally in this plot. All sensors with gold cathodes showed almost no sensitivity towards molecular oxygen in the relevant pressure range.

\section{Aerodynamic considerations}

It is important to consider that the measurements conducted on sounding rockets are intrusive because the rocket itself influences the flow field of the medium to be analyzed. The high velocities produce complex patterns of shock and rarefaction waves with regions of very different temperatures and densities than in the undisturbed atmosphere. Due to their different masses and thermal velocities the abundance of the various species may additionally be altered in the vicinity of the rocket walls (Bird, 1988). All such effects have to be taken into account when making conclusions on atmospheric properties from the measurement results. Exceptions are instruments with cryogenically cooled surfaces like the mass spectrometers flown on several missions (Offermann et al., 1981). Here incident particles are trapped on the cold walls and the shock is "frozen out" as no reflections occur. This, however, requires intensive cooling with liquid helium to temperatures below $20 \mathrm{~K}$, which dramatically increases the system complexity. Some methods may operate on a boom deployed from the rocket to probe a volume well outside of the shock front (e.g., Hedin et al., 2009). Here aerodynamic simulations are required to reveal the position and extent of the disturbances to appropriately design the detection system. In order to investigate the aerodynamic effects during the flight, we conducted simulations of the flow field at distinct points of the trajectory.

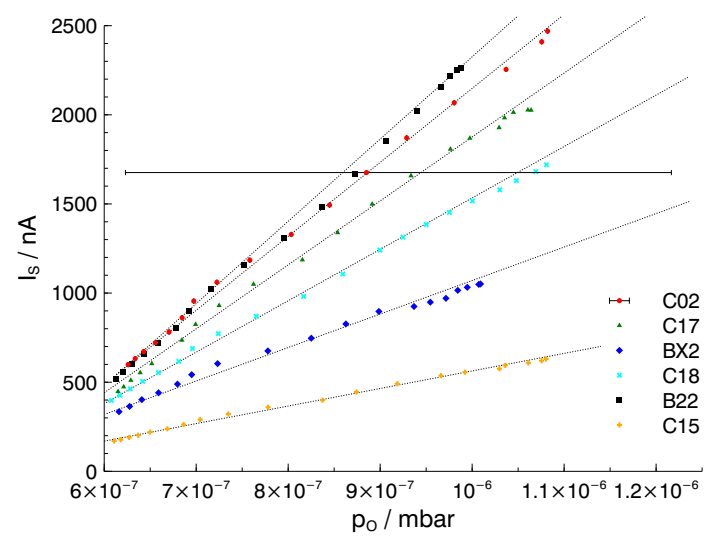

Figure 6. Calibration curves for the atomic oxygen sensors labeled C02-C15 flown on WADIS-1. Sensor currents are plotted over atomic oxygen partial pressure. The error bar represents the uncertainty due to the pressure measurement and shifted electron energy in the QMS ionizer.

These computations have to account for the transition of the flow regime from continuum to free molecular flow across the mesopause region, which cannot be treated by classical continuum mechanics. As indicated in Fig. 8, the WADIS payload had an almost vertical orientation throughout the whole experimentation phase, so three-dimensional aerodynamics have to be considered due to the horizontal velocity component. The direct-simulation Monte Carlo method (DSMC) of the PICLas code, developed in collaboration between IRS and the Institute of Aerodynamics and Gas Dynamics (IAG) (Munz, 2014), was employed to simulate the flow conditions at five points on the downleg part of the trajectory. For collisions a pairing scheme including the naturalsample-size method with a nearest-neighbor search and a standard (variable hard sphere, VHS) model was applied in which the energy-dependent collision cross section is derived from viscosity data by $\mu \propto T^{\omega}$ ( $\omega=0.75$ used). The species $\mathrm{Ar}, \mathrm{O}, \mathrm{N}_{2}$ and $\mathrm{O}_{2}$ were considered in the calculation, with a VHS reference temperature of $273 \mathrm{~K}$. For the VHS reference diameters, values of $4.17 \AA(\mathrm{Ar}), 3.1 \AA(\mathrm{O}), 4.17 \AA\left(\mathrm{N}_{2}\right)$ and $4.07 \AA\left(\mathrm{O}_{2}\right)$ were used.

The internal degrees of freedom of the molecules were taken into account while neglecting chemical reactions. Each particle in the simulation represented between $1.5 \times 10^{11}$ and $2 \times 10^{13}$ real particles (macro-particle factor, MPF). The computational domain includes an unstructured, hexahedral mesh with cell edge lengths between 3 and $50 \mathrm{~mm}$ and rectangular boundaries with minimal distances to the body ranging from 0.5 to $1.3 \mathrm{~m}$. Symmetry of the rocket was exploited by simulating only one half of the domain. The sensor heads were included in the calculation with simplified block-like geometries with the approximate size of two adjoined heads. Apart from the actual triangular configuration (see sketch in Fig. 4), two of these blocks were positioned on adjacent sides of the rocket axis in order to cover both the maxi- 


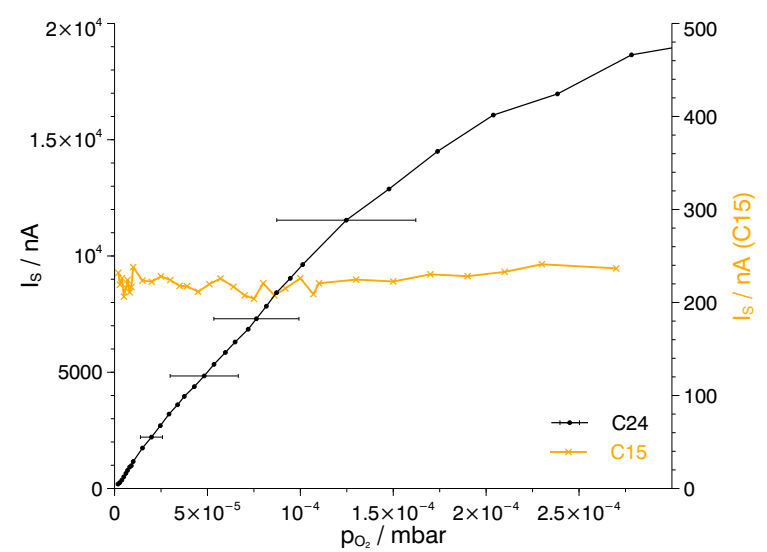

Figure 7. Calibration curves for molecular oxygen sensor C24 with platinum electrodes and for atomic oxygen sensor $\mathrm{C} 15$ with goldplated cathode. Sensor currents are plotted over the $\mathrm{O}_{2}$ partial pressure. The error bars indicate the uncertainty due to the pressure measurement.

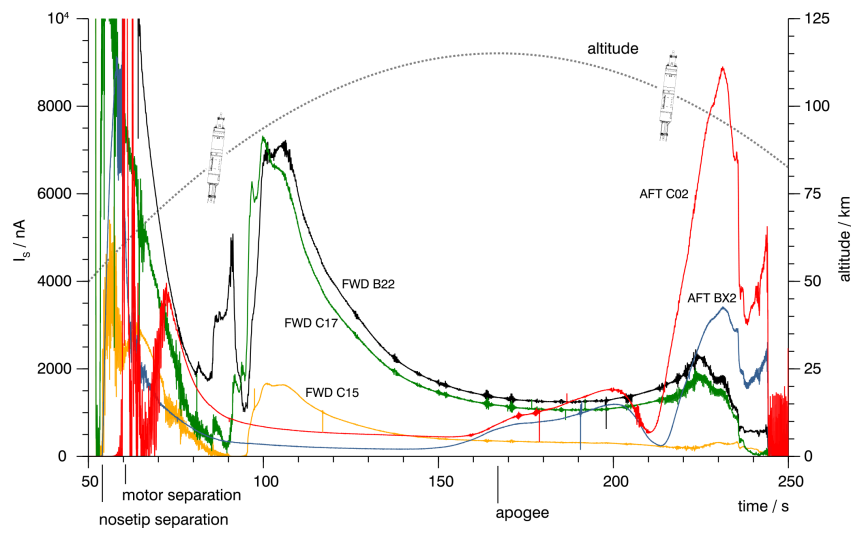

Figure 8. Raw signals of the atomic oxygen sensors vs. flight time, together with the altitude and rocket orientation during the experimentation phase.

mal and minimal particle density cases during one revolution of the rocket. On the walls a diffusive reflection with full accommodation and a temperature of $300 \mathrm{~K}$ were assumed, whereas specular reflection was set for the plane of symmetry. All other boundaries were open with an inflow from a virtual buffer layer filled with particles of a MaxwellBoltzmann distribution corresponding to the free-stream condition. Steady state, i.e. start of averaging of macroscopic values, such as particle density, was assumed to be reached after $0.02 \mathrm{~s}$. The gas composition at the different altitudes was taken from the standard MSIS-E-90 model and temperatures from the CONE results, where it is derived by integrating the measured neutral air density profile (Rapp et al., 2001). Sensitivity analyses were conducted in terms of varying boundary distances and MPFs. Computing time for the simulations ranged from 0.5 to $4 \mathrm{~h}$ on 96 cores of a CRAY XC40 for altitudes above $85 \mathrm{~km}$ and was $10 \mathrm{~h}$ on 192 cores
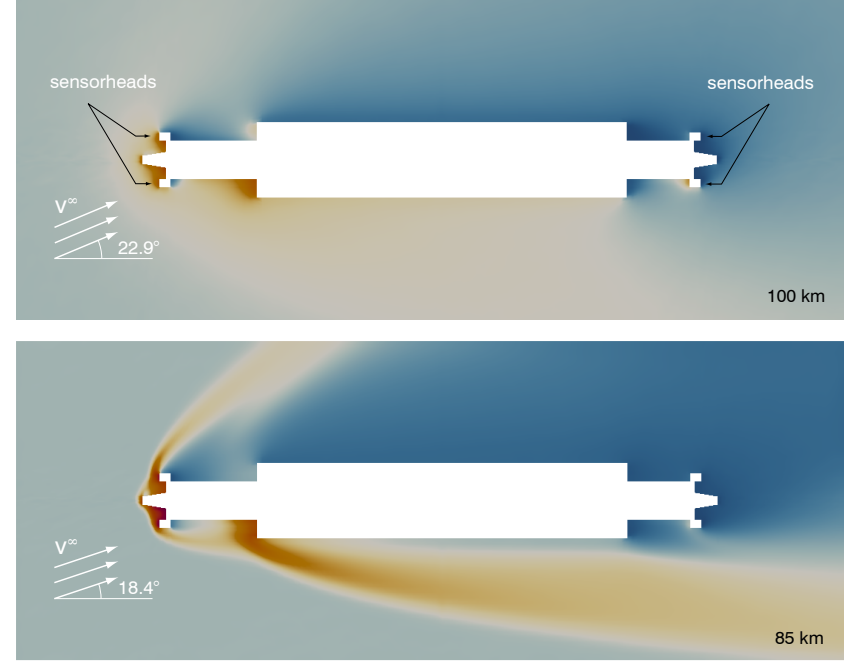

$0.0+1+1+1^{2}+3^{3}+4^{4}+5^{5} \cdot 5.9 \mathrm{n} / \mathrm{n}^{\infty}$

Figure 9. Distribution of the ratio between local and free-stream number density during the downleg at two different altitudes. Results from 3D DSMC calculations with the PICLas code.

for the $85 \mathrm{~km}$ case. Flow field results for 85 and $100 \mathrm{~km}$ altitude are given exemplarily in Fig. 9. Here the ratio of the local total number density $(n)$ to the value of the undisturbed atmosphere $\left(n^{\infty}\right)$ is plotted. At $85 \mathrm{~km}$ a distinct shock is formed with pronounced ram and wake regions that are blurred towards higher altitudes. The values of $n / n^{\infty}$ on the upwind side at the sensor position are given in Fig. 10 as a function of altitude, with one line each representing the ram and wake sensors. The $n / n^{\infty}$ values were multiplied to the measurement results to correct for aerodynamic effects. For computational reasons only the total number densities could be considered for this ratio; in previously published simulations, however, the relative abundance of $\mathrm{O}$ was shown to vary only slightly (Hedin et al., 2009).

\section{Results}

In the following the results from the FIPEX measurements before and after aerodynamic correction are given. Number densities are calculated from the raw sensor signals by applying the linear relationships obtained from the individual calibration curves. The results are subsequently corrected for aerodynamic effects by dividing them by the appropriate ram or wake factors obtained from the numerical simulations. These factors were linearly interpolated for all altitudes from the curves given in Fig. 6. Emphasis is placed on the atomic oxygen density profiles; values for molecular oxygen, obtained from the platinum cathode sensors, are presented briefly. Interpretation of the PHLUX results still requires a thorough analysis, which will be given in a companion paper. 


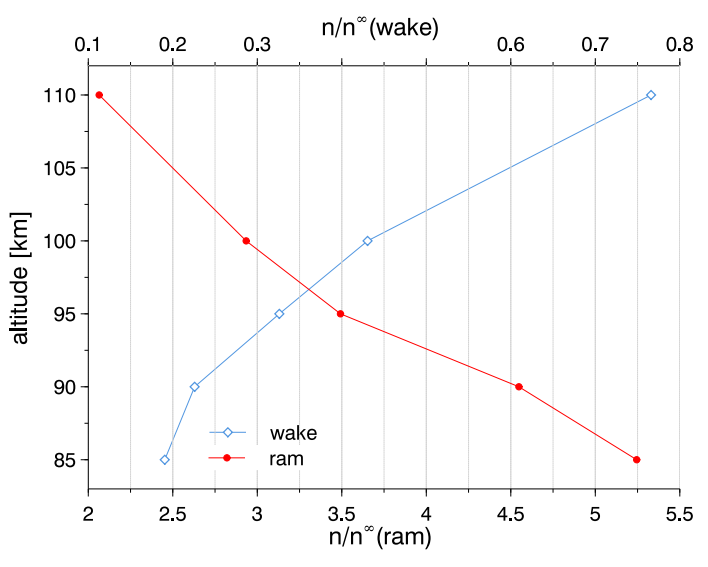

Figure 10. Ratios between local and free-stream total number density at the sensor position as a function of altitude. The ratios are obtained from numerical simulations made at the marked altitudes and are used as aerodynamic correction factors.

\subsection{FIPEX - atomic oxygen profiles}

An overview of the raw signals obtained from all atomic oxygen sensors is given in Fig. 8. The values are plotted vs. the duration of the flight, together with the altitude and significant events. Additionally the orientation of the rocket payload with instrument decks on both ends is shown. Due to their alignment the sensors were affected by the horizontal component of the flight velocity. As the rocket was spinstabilized, this resulted in a signal modulated with a $2.9 \mathrm{~Hz}$ component that was removed with a notch filter. One sensor on the lower deck showed unstable oscillations in the signal and was excluded from further analysis, so that in total results from five $\mathrm{O}$ sensors could be used. After application of the respective calibration curves, atomic oxygen partial pressures were obtained. Number densities were calculated by dividing by $k T$, were $k$ is Boltzmann's constant and $T$ the local absolute temperature measured with high spatial resolution by the CONE instrument. Temperature data were not available for altitudes above $110 \mathrm{~km}$. The apogee of the trajectory was $115 \mathrm{~km}$.

\subsubsection{Fore sensors}

Data obtained from the fore sensors before aerodynamic correction are given in Fig. 11. Corrected profiles are plotted in Fig. 14. In the initial phase, after nosecone separation at $53 \mathrm{~km}$ altitude, the sensors had to acclimatize to the lowdensity conditions of the free atmosphere. Gases that have been adsorbed on the electrodes under atmospheric pressure before liftoff desorb from the surface. This process leaves the sensors in unstable condition, and hence they show very different results in the beginning. They measured in the rocket ram during ascent and stayed in the wake during descent. The profiles are plotted from an altitude of $80 \mathrm{~km}$ upwards, where they converge at $91 \mathrm{~km}$ to form a sharp rise in atomic oxygen

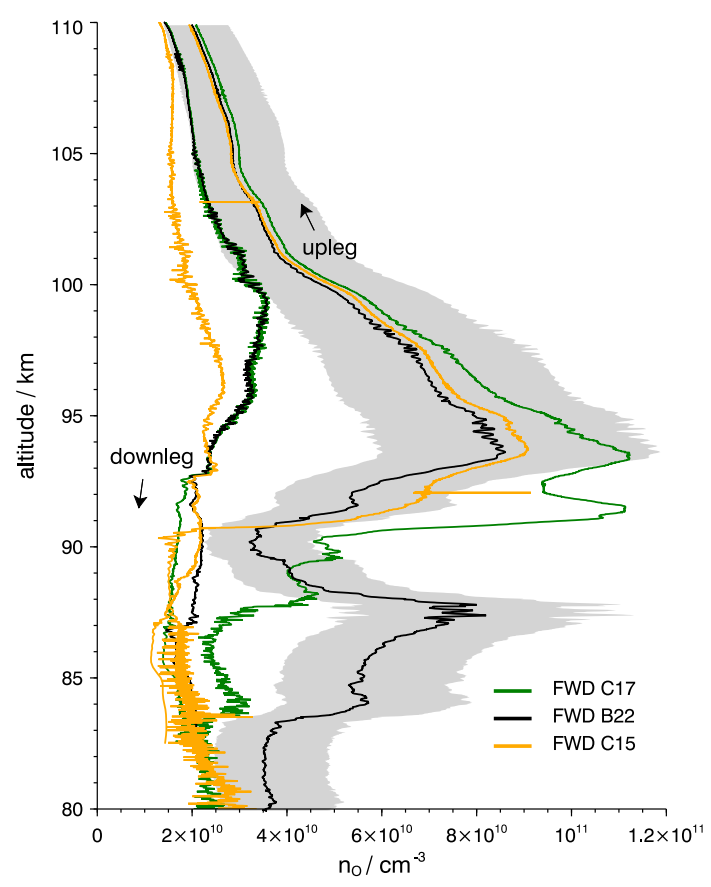

Figure 11. Measurement results for atomic oxygen number density vs. altitude for sensors on the fore deck during the up- and downleg without aerodynamic correction. The shading shows the uncertainty from the calibration for fore sensor B22.

number density. From that point onwards the curves follow each other qualitatively with a maximum value at $93.6 \mathrm{~km}$ altitude. During the downleg variations in the $\mathrm{O}$, density can still be resolved, with two profiles closely matching (C17 and $\mathrm{B} 22)$, while the third one (C15) differs. The characteristics obtained by the first mentioned sensors are similar to the ascent results while their magnitude is reduced, with fewer details than during upleg.

\subsubsection{Aft sensors}

The motor was separated at an altitude of $60.9 \mathrm{~km}$ releasing the lower instrument deck. Profiles recorded by the aft sensors are plotted in Fig. 12, again without application of the aerodynamic correction factors. Corrected results are included in Fig. 14. While in the wake, during ascent, no density variations could be determined. For both sensors the downleg profile is dominated by a deep dip with a minimum between 104 and $106 \mathrm{~km}$, followed by a gradual rise that peaks at $96 \mathrm{~km}$ altitude. Below that point a characteristic sharp gradient and small-scale variations are observed, followed by a sharp gradient at an altitude of $87 \mathrm{~km}$. The high-frequency fluctuations in the lower part of the curves are probably leftovers from the rocket spin. The payload enters a flat spin at around $68 \mathrm{~km}$, which terminates the measurements. Below $85 \mathrm{~km}$ the results suffer from increasing noise due to the onset of instability in the flight state. 


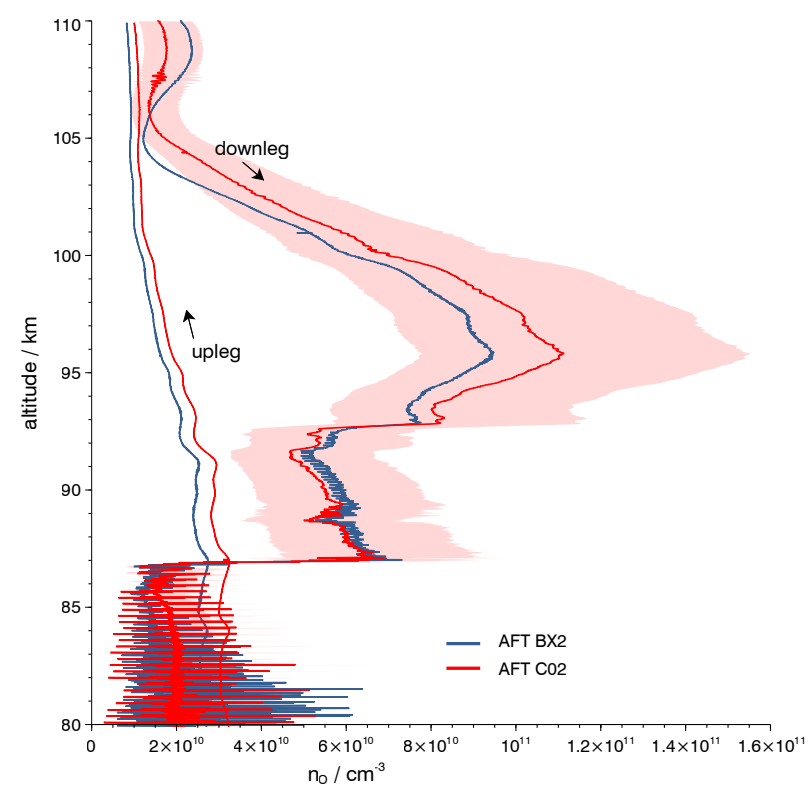

Figure 12. Measurement results for atomic oxygen number density vs. altitude for sensors on the aft deck during the up- and downleg without aerodynamic correction. The shading shows the uncertainty from the calibration for the aft sensor $\mathrm{CO} 2$.

\subsection{FIPEX - molecular oxygen}

Results for the molecular oxygen number density recorded by sensor C24 (fore deck) during the upleg and downleg after aerodynamic correction with the ram and wake factors, respectively, are plotted exemplarily in Fig. 13. Here the calibration curve given in Fig. 7 was applied to the raw signal after filtering out the spin modulations. This practice neglects the fact that the platinum electrodes also respond to atomic oxygen, although with a different characteristic than to $\mathrm{O}_{2}$ due to differing adsorption kinetics.

The probability of finding suitable neighboring adsorption sites on the surface for both atoms is lower than in the case of a single incident $\mathrm{O}$ atom. The complete calibration of a platinum sensor for mixtures of $\mathrm{O}_{2}$ and $\mathrm{O}$ is therefore more complex than in the case of gold electrodes that do not respond to molecular oxygen. For this reason the results cannot be understood as pure $\mathrm{O}_{2}$ profiles but represent in some way the sum of atomic and molecular oxygen number densities. An approximate equation describing the total signal of a sensor with platinum electrodes as a sum of the contributions from $\mathrm{O}$ and $\mathrm{O}_{2}$ is given in Förstner (2003). However, in order to separate the measured currents into their components, detailed knowledge of electrode properties such as their surface area, total number of adsorption sites or adsorption probabilities of the species is required. The fact that up- and downleg profiles are very close in their absolute values is an indication of realistic numerical modeling of the aerodynamics, resulting in appropriate correction factors for both ram and wake sensors.

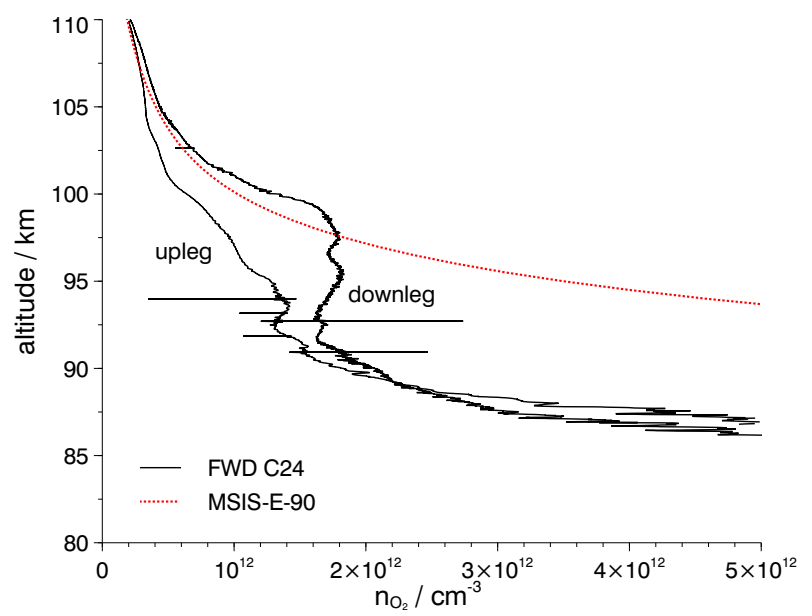

Figure 13. Profile for the $\mathrm{O}_{2}(+\mathrm{O})$ number density from fore sensor C24 after aerodynamic correction (ram for upleg, wake for downleg) compared to MSIS-E-90.

\section{Discussion}

The FIPEX density profiles after application of the aerodynamic corrections are given in Fig. 14. Additionally, data is compared to the standard MSIS-E-90 model. Though having been measured in different geophysical conditions, profiles obtained during the NLTE-2 campaign - launched at the Esrange Space Center, northern Sweden, on 6 March 1998 - are additionally included for comparison (Hedin et al., 2009). A fair agreement is observed for the altitude of maximum $\mathrm{O}$ number densities between the FIPEX results and the MSIS and NLTE-2 data. FIPEX profiles peak at 93.6 and $96 \mathrm{~km}$ for the up- and downleg, respectively. The MSIS-E-90 curve shows a peak value at $93.5 \mathrm{~km}$, and the NLTE- 2 measurements recorded a maximum at $97.5 \mathrm{~km}$ altitude. The NLTE-2 results have a much higher spatial resolution (smoothed to $250 \mathrm{~m}$ on the vertical axis) than the MSIS profile and feature several distinct local extrema. The absolute peak values for $n_{\mathrm{O}}$ from MSIS and NLTE-2 are higher than the FIPEX results by factors of 5 and 14, respectively. Both fore and aft sensors recorded variations in atomic oxygen number density on a scale that is beyond the spatial resolution of the MSIS-E-90 and NLTE- 2 profiles. The results show local extrema that can mostly be found in the curves recorded from the others sensors on the same instrument deck, while they differ slightly in altitude and absolute value between uplegfore and downleg-aft measurements. These differences are intended to be linked to horizontal variations in $\mathrm{O}$ density as the trajectory spans over a distance of about $30 \mathrm{~km}$ at $80 \mathrm{~km}$ altitude. The broad minimum observed in the downleg-aft profiles at around $105 \mathrm{~km}$ altitude is, however, most likely not due to actual large variations in the atomic oxygen concentration; the fore sensor data do not show this feature. One attempt to explain this situation could be made by assuming the onset of outgassing on the rocket rear side beyond 
apogee. The surfaces would heat up due to an evolving bow shock releasing adsorbed particles, e.g., exhaust gases, that consume atomic oxygen in chemical reactions. However, the increase in surface temperature measured by the PHLUX sensors between apogee and $105 \mathrm{~km}$ was only about $0.5 \mathrm{~K}$, so that outgassing does not seem to cause an atomic oxygen depletion. We favor an interpretation based on the electrode kinetics. As laid out before, the reference voltage of the sensor is regulated to a constant value by appropriately adjusting $U_{S}$, the voltage between anode and cathode. With increasing oxygen concentration $U_{S}$ has to be raised which leads to a linear characteristic of the sensor current over a wide pressure range. Under steady-state conditions a given oxygen density can be attributed to a certain ratio of $U_{S}$ and $I_{S}$ values. During the downleg a rise in this ratio along with a decline in the absolute $U_{S}$ value can be found in the aft sensor data (see Fig. 15) exactly at the altitude where the dip in $\mathrm{O}$ density was observed. Although the gold coated cathode is not sensitive towards molecular oxygen, the platinum reference electrode still dissociatively adsorbs $\mathrm{O}_{2}$. Its reduction to $\mathrm{O}^{2-}$ consumes electrons, which increases the potential difference between reference and cathode. Subsequently $U_{S}$ is lowered by the controller to maintain a constant reference voltage, leading to a decrease in $I_{S}$. This mechanism is believed to cause the dip in the signal after the sensors left the rocket wake with a very low $\mathrm{O}_{2}$ density beyond apogee. At very low ambient pressures the coverage of the electrode surfaces with adsorbed oxygen is also low. For two reasons the coverage on the cathode is further reduced compared to the other electrodes: firstly, gold prevents adsorption of molecular oxygen with only very low $\mathrm{O}$ concentrations in the rocket wake; secondly, adsorbed $\mathrm{O}$ is pumped away by the applied voltage $U_{S}$. Surface diffusion to the triple-phase boundary is slowed down at these low coverages so that a steady state is reached only after long periods (Förstner, 2003, p. 106). The described slow kinetics may also explain the delayed onset of the effect some seconds beyond apogee. Further investigations into the transient reaction of the sensors at very low pressures have to be carried out; this will also help to improve the interpretation of high-frequency variations of the results in that regime.

Generally speaking, the results recorded in the ram, i.e. the fore-upleg and aft-downleg profiles, appear to reflect the actual variations better than their counterparts in the wake. In the ram the measurements are also influenced by aerodynamic effects, but the response to density variations is obviously more direct, showing fluctuations on a smaller scale with a better signal-to-noise ratio.

A comparison of the fore and aft results during the downleg is given in Fig. 16, together with the MSIS-E-90 profile, which has been scaled by a factor of 0.5 . The curves have been corrected by the aerodynamic factors for ram and wake, respectively. Though different in magnitude, the obtained profiles agree widely on a qualitative basis. Smallscale features are represented in all curves, e.g., the short dip

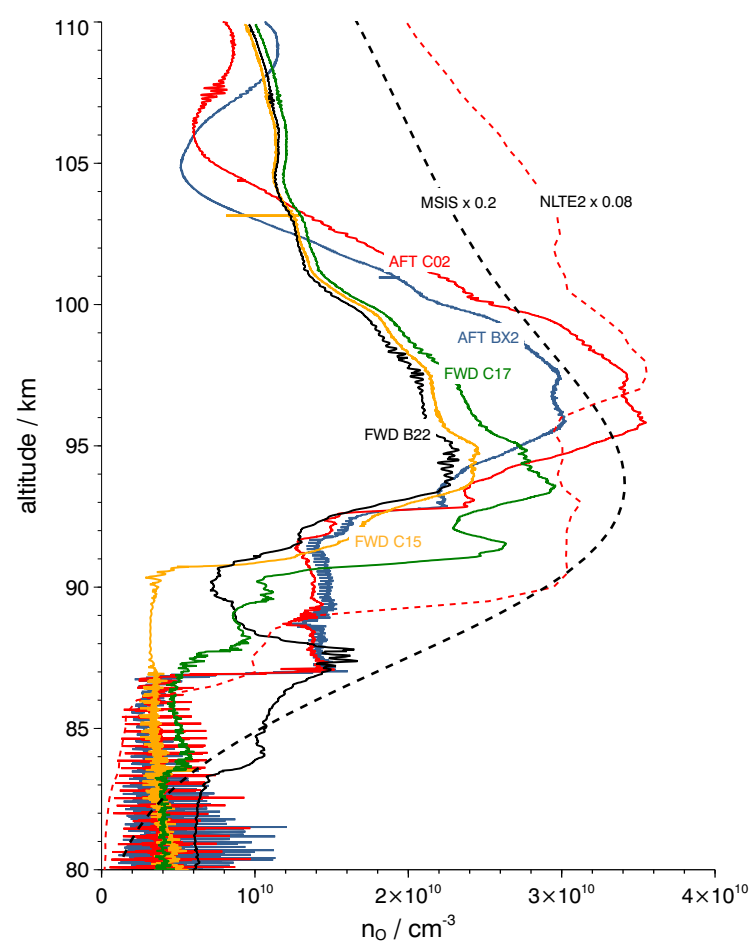

Figure 14. Profiles of $\mathrm{O}$ number density for FIPEX sensors on fore and aft deck after aerodynamic ram correction. Downleg profile for aft sensors, upleg part for the fore sensors. Comparison to MSIS model and NLTE-2 measurements.

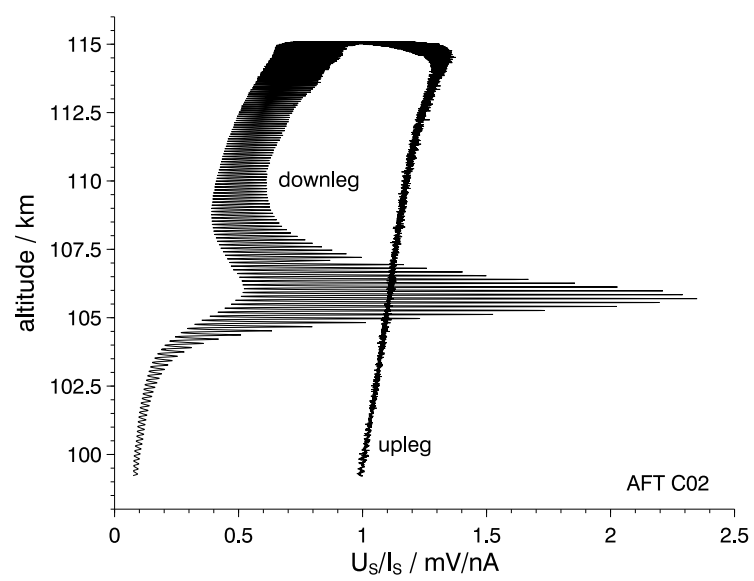

Figure 15. Ratio of voltage to current for an aft sensor during the downleg. Raw values including $2.9 \mathrm{~Hz}$ modulation due to rocket spin.

at $89 \mathrm{~km}$ altitude or the steps at 87 and $93 \mathrm{~km}$. The fact that these results are simultaneously recorded at opposite ends of the rocket with different sensors on individual electronics increases confidence that actual atmospheric $\mathrm{O}$ density variations were measured. The deviation between the profiles of one side, especially among the fore sensors, is most likely caused by the $U_{S}$ voltage control. The course of $U_{S}$ during 


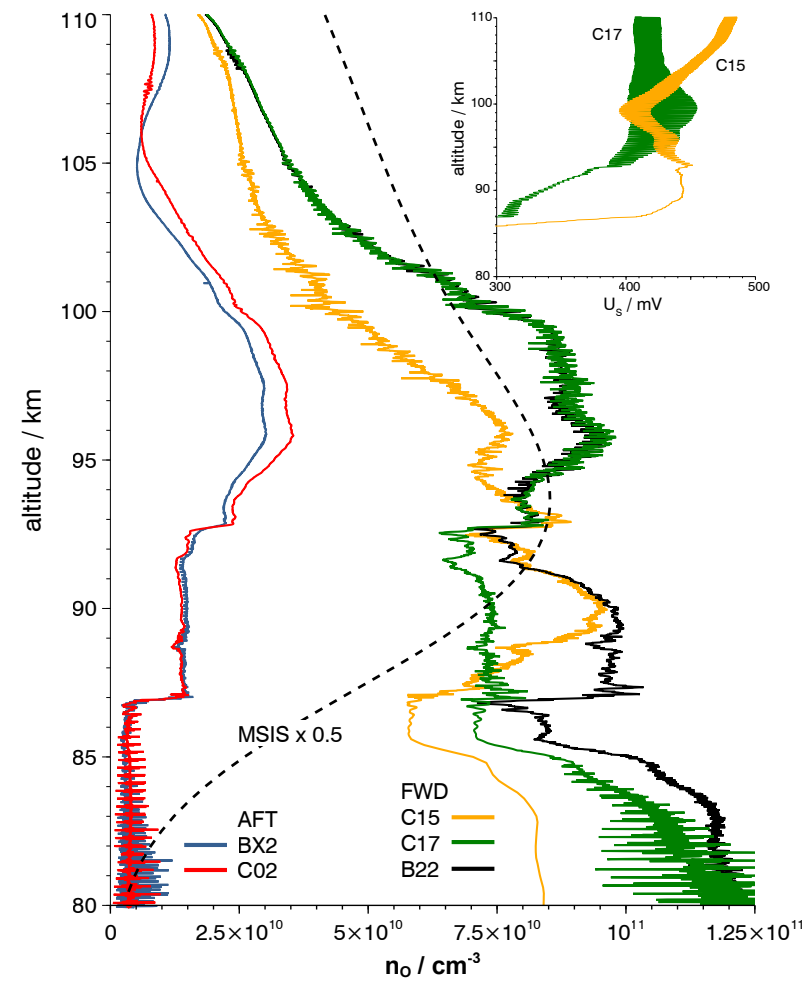

Figure 16. Comparison of $\mathrm{O}$ number density profiles from sensors on fore and aft deck during the downleg after aerodynamic correction (ram factors for aft, wake factors for fore). The MSIS profile is scaled by 0.5 and plotted additionally. The inset shows the course of the sensor voltage $U_{S}$ (including $2.9 \mathrm{~Hz}$ modulation from rocket spin) for two fore sensors.

the downleg is given in the inset of Fig. 16. These curves reflect the large-scale differences obtained in the number densities from the single sensors. A $U_{S}$ voltage control in combination with electrodes from different materials (golden cathode, platinum anode and reference) apparently accentuates deviations between the sensor properties that are due to the mentioned manufacturing tolerances. Variations in the ratios of the surfaces and of the triple-phase boundaries between the golden cathode and the other electrodes can thus lead to a different controlling behavior in a mixed $\mathrm{O}_{2} / \mathrm{O}$ atmosphere. While the voltage control is a versatile instrument to maintain stable conditions on the cathode for sensors with electrodes made from identical materials, e.g., all-platinum electrodes for sensing pure $\mathrm{O}_{2}$, it seems to corrupt the measurements in the present case.

\section{Uncertainties, sources of error and recommendations}

Several possible sources of errors and uncertainties in the calibration procedure as well as during the flight experiment can be identified and are addressed in the following. During calibration the sensors are exposed to atomic oxygen produced in a microwave discharge. The atoms might be accompanied by other oxygen species influencing the sensor signal, with a focus on ozone $\left(\mathrm{O}_{3}\right)$ and electronically excited molecular oxygen $\mathrm{O}_{2}^{*}$, especially in its long-lived ${ }^{1} \Delta_{\mathrm{g}}$ state (so-called singlet oxygen). In both cases it is important to investigate whether the species can contribute to the measured sensor current and if they are actually present in the experiment. In order to answer the first question, the initial step of the electrode reactions, the adsorption on the gold surface, is regarded. It can be found in the literature that ozone does adsorb on gold and hence will be part of the reaction chain forming the sensor signal (Saliba et al., 1998; Kim et al., 2006). For singlet oxygen, relevant literature is very rare; there are practically no publications that examine if $\mathrm{O}_{2}^{*}$ is, in contrast to ground state $\mathrm{O}_{2}$, adsorbed on gold surfaces or not. A hint is given in the work by Gottfried et al. (2002), where weakly bound physisorbed oxygen is adsorbed by electron bombardement. They discuss that a threshold electron energy of $3.5 \mathrm{eV}$ is required for this process. The excitation energy of $\mathrm{O}_{2}{ }^{1} \Delta_{\mathrm{g}}$ is listed, on the other hand, as $0.98 \mathrm{eV}$ (Herzberg, 1950). On that basis it could be speculated that this species does not possess the necessary activation energy for adsorption, although the two underlying processes are different. The abundance of ozone during calibration was checked by recording the QMS signal at mass number 48. Only minute trace amounts of ozone could be found, although the cross section for electron impact ionization of $\mathrm{O}_{3}$ in the QMS ion source is higher than for $\mathrm{O}_{2}$ (McConkey et al., 2008). Ozone is not produced directly in the discharge but in its afterglow via recombination of atomic oxygen (Normand et al., 1995). In the present setup the afterglow is too short to release significant amounts of ozone into the vacuum chamber. The detection of $\mathrm{O}_{2}^{*}$ is, however, not straightforward. We employed a method that seeks to identify singlet oxygen in the threshold ionization curves obtained by scanning the electron energy in the QMS ionizer (Herron and Schiff, 1958; Pulpytel et al., 2005). Excited molecules are already ionized at lower electron energies and so leave traces in the curves at energies lower than the appearance potential of the ground state molecule. In order to avoid production of excited species from other sources, all ionization gauges were turned off during the experiments. Curves with scanning electron energies were recorded for both plasma-on and plasma-off conditions, with the energy scale calibrated against the appearance potential of argon. The curves were normalized to their value at $40 \mathrm{eV}$ and averaged over about 100 single scans. In both cases the results were identical and did not confirm the presence of $\mathrm{O}_{2}^{*}$. Though it is most likely produced in the microwave discharge, it probably suffers from deactivation at the silica walls during the passage through the orifice. With a diameter of $0.3 \mathrm{~mm}$ and a length of $2.5 \mathrm{~mm}$ it forms a narrow tunnel where multiple wall collisions occur before the molecules exit into the high vacuum. It should be noted, however, that in contrast to the calibration conditions both ozone and $\mathrm{O}_{2}\left({ }^{1} \Delta_{\mathrm{g}}\right)$ have been measured in the atmosphere aboard sounding rockets, with peak densities at $90 \mathrm{~km}$ altitude of 
about $1 \times 10^{8}$ and $3 \times 10^{9} \mathrm{~cm}^{-3}$ for ozone and $\mathrm{O}_{2}\left({ }^{1} \Delta_{\mathrm{g}}\right)$, respectively (Gumbel et al., 1998). These species could then contribute to the uncertainties in the atomic oxygen measurements. It is therefore important to further investigate their effect on the sensor signals.

It was revealed in recent experiments that the electron energy in the QMS ionizer is influenced by the microwave plasma and thus can deviate from its nominal value. More precisely, it is shifted to lower energies when the discharge is turned on. This shift, however, affects the QMS results both for $\mathrm{O}_{2}$ and for atomic oxygen. Their ratio is the relevant quantity for the calibration, and with an observed energy deviation of $1.5 \mathrm{eV}$ the measured atomic oxygen density would be lower by $8 \%$, based on the literature values for electron impact ionization (Laher and Gilmore, 1990; McConkey et al., 2008). Calibration of the QMS is done by recording its readings at a series of partial pressures of $\mathrm{O}_{2}$ and $\mathrm{CH}_{4}$, respectively, compared to the output from a cold cathode gauge (Pfeiffer PKR 251) with an accuracy of $\pm 30 \%$. The correction factor for $\mathrm{CH}_{4}$ of the cold cathode gauge was found with the aid of a precise, gas-type independent capacitance manometer (MKS Baratron 690A, accuracy $\pm 0.12 \%$ ) in the pressure range above $10^{-6}$ mbar. Linearity was assumed below that point.

A shortcoming of the calibration method in its present form is its inability to cover the complete range of atomic oxygen number densities encountered during the flight experiment. The sensor currents measured along the trajectory (see Fig. 8) exceed the signals given in the calibration curves (see Fig. 6). Their linear characteristics had to be extrapolated by a factor of approximately 3.5. However, at a certain pressure the respective curves will become nonlinear. This is a gradual transition and depends on parameters such as material, surface, geometry and temperature of the electrodes and the electrolyte. If the flux of oxygen delivered by the electrodes via surface diffusion exceeds the rate at which it can be transported to the anode, the current-pressure curve flattens. For the molecular oxygen sensors this is observed at currents beyond $10 \mu \mathrm{A}$ (see Fig. 7). The O sensors differ in a thin layer of gold on the cathode, which will only very slightly alter its total surface area or the length of the three phase boundary, so a linear behavior is assumed here up until the levels observed in the flight. Neglecting an actual nonlinearity in the characteristics, however, would lead to an underestimation of the number densities. A major uncertainty during the flight is due to the sensor voltage $U_{S}$. As laid out before, the golden cathode is widely inert towards molecular oxygen, but the other electrodes are not. This means that the controller may adjust a $U_{S}$ different to the value during calibration if the $\mathrm{O} / \mathrm{O}_{2}$ ratios in both cases differ. Apart from the "dip" in the profiles discussed earlier this also affects the total signal level. In fact, sensor voltages of less than half of the value applied during calibration were observed. There is, however, no direct linear relation between $U_{S}$ and $I_{S}$; this depends largely on pressure and oxygen coverage of the elec- trodes. It is therefore hardly possible to recover the true signal based on the knowledge of the true $U_{S}$ value. Nevertheless we estimate that the recorded signals could be lower by $50 \%$ due to this effect. A clue about the total accuracy of the present methods can be obtained by comparing the absolute values of the results given in Fig. 16. If the uncertainties from the calibration are taken into account, then the atomic oxygen number densities at the $96 \mathrm{~km}$ peak differ by a maximum factor of about 6.4 between the fore and aft sensors during the downleg. This includes the aerodynamic correction based on the numerical simulations. The results from the fore sensors here suffer from a lower signal-to-noise ratio, and the rise in $\mathrm{O}$ density below $85 \mathrm{~km}$ most likely does not reflect the actual conditions. If the ram and wake factors are assumed to be correct, based on the consistent results of the $\mathrm{O}_{2}$ sensor in Fig. 13, then the high signals in the ram obviously underestimate the true number density. As discussed before, this would be the case for an actual nonlinearity in the calibration curves. A further indication of such nonlinear characteristics can be found regarding the magnitude of the rise in $\mathrm{O}$ concentration between $80 \mathrm{~km}$ altitude and the peak values at about $95 \mathrm{~km}$. The results at the lower end of the profiles coincide well with the values measured in the NLTE campaign. A more appropriate comparison is the NLC-93 campaign, launched in geophysical conditions similar to the WADIS-1 flight (July-August, nighttime but sunlight at a high latitude), which also shows corresponding results for the low altitudes (Gumbel et al., 1998). The values at $80 \mathrm{~km}$ are given as $3.2 \times 10^{9} \mathrm{~cm}^{-3}$ (NLTE) and $2.4 \times 10^{9} \mathrm{~cm}^{-3}$ (NLC93), and the present data read $3.4 \times 10^{9} \mathrm{~cm}^{-3}$ for the aft sensors during the downleg. However, the rise in $\mathrm{O}$ density to the peak value is clearly smaller than in the mentioned references. A nonlinearity in the sensor characteristics could again be responsible for this underestimation of the high densities. The maximum difference in the results between the aft sensors alone is below $15 \%$, which leads to the conclusion that accurate measurements with the described technique are possible if the discussed sources of error can be ruled out in future experiments.

For upcoming missions the use of sensors with all-golden electrodes should be considered to eliminate the issues generated by different reactions on different electrode materials. A further consequence of the findings described here might be an operation of sensors with a fixed $U_{S}$, i.e. without regulating the reference voltage. This helps to maintain the electrical conditions used during laboratory calibrations at the expense of increased nonlinearity of the calibration curve.

A way to shorten the initial unstable accommodation phase, observed especially for the front sensors, could be to cover the sensor heads with an evacuated housing that is separated together with the nose cone or the motor. Such a procedure has already been realized for the CONE instrument. The housing should be pumped down to the pressure expected at the altitude of separation in order to minimize the desorption of gases from the electrodes. 


\section{Conclusions}

The FIPEX instrument, based on solid electrolyte sensors, was for the first time used to measure atomic oxygen number densities on a sounding rocket and has successfully recorded profiles along the trajectory of WADIS-1. On a qualitative basis the results compare well with the MSIS standard atmosphere and the profiles obtained in the NLTE-2 campaign. Measurements with the PHLUX instrument were complicated by solar radiation and require further analysis. The absolute values derived from FIPEX data in the ram are by factors of around 5 and 13 lower than the mentioned references. The wake results on the contrary peak at values reduced by factors of 1.8 and 4.6 , respectively. This might be due to nonlinearities in the sensor characteristics at higher atomic oxygen densities that could not be covered in the laboratory calibration. Here further investigations are needed. Controlling of the sensor voltage in combination with electrodes made from different materials was identified as a key source of uncertainties during the flight. For upcoming missions the use of sensors with all golden electrodes should be considered, which may eliminate disturbances through different reactions of oxygen on platinum and gold electrodes. The measurements stand out due to a unprecedented high spatial resolution, showing $\mathrm{O}$ density variations on very small vertical scales. The sensors are small and lightweight and thus enable symmetrical instrumentation on fore and aft deck in order to measure profiles both during the up- and downleg in the same ram or wake conditions. This facilitates the detection of $\mathrm{O}$ density variations on a horizontal scale.

Acknowledgements. This work has been funded by the German Aerospace Center. We thank J. Hedin from MISU, Stockholm, for providing the NLTE data and B. Strelnikov, IAP Kühlungsborn, for the CONE temperature results. We appreciate the work from M. Hartling, IRS electronics lab, who designed the sensor electronics. The efforts of DLR MORABA and the support during the launch campaign are highly recognized. The platinum electrode sensors have been produced by ESCUBE GmbH in collaboration with our institute.

Edited by: D. Heard

\section{References}

Agarwal, S., Quax, G., van de Sanden, M. C. M., Maroudas, D., and Aydil, E.: Measurement of absolute radical densities in a plasma using modulated-beam line-of-sight threshold ionization mass spectrometry, J. Vac. Sci. Technol. A, 22, 71-81, doi:10.1116/1.1627767, 2004.

Bird, G. A.: Aerodynamic Effects on Atmospheric Composition Measurements from Rocket Vehicles in the Thermosphere, Planet. Space Sci., 36, 921-926, doi:10.1016/00320633(88)90099-2, 1988
Fasoulas, S., Förstner, R., and Stöckle, T.: Flight Test of Solid Oxide Micro-Sensors on a Russian Reentry Probe, in: Space 2001 Conference \& Exhibition, AIAA 2001-4724, doi:10.2514/6.20014724, 2001.

Förstner, R.: Entwicklung keramischer Festelektrolytsensoren zur Messung des Restsauerstoffgehalts im Weltraum, PhD thesis, Institut für Raumfahrtsysteme, Universität Stuttgart, 160 pp., 2003.

Friedrich, M., Torkar, K. M., Hoppe, U.-P., Bekkeng, T.-A., Barjatya, A., and Rapp, M.: Multi-instrument comparisons of Dregion plasma measurements, Ann. Geophys., 31, 135-144, doi:10.5194/angeo-31-135-2013, 2013.

Gottfried, J., Schmidt, K. J., Schroeder, S. L. M., and Christmann, K.: Spontaneous and electron-induced adsorption of oxygen on $\mathrm{Au}(110)-(1 \times 2)$, Surf. Sci., 511, 65-82, doi:10.1016/S00396028(02)01555-8, 2002.

Gritzner, C. and Rapp, M.: ECOMA and WADIS, DLR Countdown, $15,2011$.

Gritzner, C. and Strelnikov, B.: Rough Seas in the Middle Atmosphere, DLR Countdown, 23, 2013.

Gumbel, J., Murtagh, D. P., Espy, P. J., Witt, G., and Schmidlin, F. J.: Odd oxygen measurements during the Noctilucent Cloud 93 rocket campaign, J. Geophys. Res.-Space, 103, 23399-23414, doi:10.1029/98JA02155, 1998.

Hammer, B., Hansen, L. B., and Norskov, J. K.: Improved adsorption energetics within density-functional theory using revised Perdew-Burke-Ernzerhof functionals, Phys. Rev. B, 59, 74137421, doi:10.1103/PhysRevB.59.7413, 1999.

Hedin, J., Gumbel, J., Khaplanov, M., Witt, G., and Stegman, J.: Optical studies of noctilucent clouds in the extreme ultraviolet, Ann. Geophys., 26, 1109-1119, doi:10.5194/angeo-26-11092008, 2008.

Hedin, J., Gumbel, J., Stegman, J., and Witt, G.: Use of $\mathrm{O}_{2}$ airglow for calibrating direct atomic oxygen measurements from sounding rockets, Atmos. Meas. Tech., 2, 801-812, doi:10.5194/amt2-801-2009, 2009.

Herdrich, G., Auweter-Kurtz, M., Fertig, M., Löhle, S., Pidan, S., and Winter, M.: Present Design of the Flight Instrumentations Pyrex, Phlux and Respect for the Capsule Expert, in: Fifth European Symposium on Aerothermodynamics for Space Vehicles, edited by: Danesy, D., vol. 563 of ESA Special Publication, 401408, 2005.

Herron, J. T. and Schiff, H. I.: A Mass Spectrometric Study of Normal Oxygen and Oxygen subjected to Electrical Discharge, Can J. Chemistry, 36, 1159-1170, doi:10.1139/v58-170, 1958.

Hertz, J. L.: Microfabrication Methods to Improve the Kinetics of the Yttria Stabilized Zirconia-Platinum-Oxygen Electrode, $\mathrm{PhD}$ thesis, Massachusetts Institute of Technology, 194 pp., 2006.

Herzberg, G.: Molecular spectra and molecular structure. Vol.1: Spectra of diatomic molecules, Van Nostrand Reinhold, New York, 686 pp., 1950.

Kim, J., Samano, E., and Koel, B. E.: Oxygen adsorption and oxidation reactions on $\mathrm{Au}(211)$ surfaces: Exposures using $\mathrm{O}_{2}$ at high pressures and ozone $\left(\mathrm{O}_{3}\right)$ in UHV, Surf. Sci., 600, 4622-4632, doi:10.1016/j.susc.2006.07.057, 2006.

Laher, R. R. and Gilmore, F. R.: Updated Excitation and Ionization Cross Sections for Electron Impact on Atomic Oxygen, J. Phys. Chem. Ref. Data, 19, 277-305, doi:10.1063/1.555872, 1990. 
Lebedev, Y.: Microwave discharges: generation and diagnostics, J. Phys. Conf. Ser., 257, 012016, doi:10.1088/17426596/257/1/012016, 2010.

Légaré, P., Hilaire, L., Sotto, M., and Maire, G.: Interaction of oxygen with Au surfaces: A LEED, AES and ELS study, Surf. Sci., 91, 175-186, doi:10.1016/0039-6028(80)90078-3, 1980.

Löhle, S., Battaglia, J.-L., Batsale, J.-C., Enouf, O., Dubard, J., and Filtz, R.-R.: Characterization of a Heat Flux Sensor Using Short Pulse Laser Calibration, Rev. Sci. Instrum., 78, 053501, doi:10.1063/1.2736388, 2007.

Löhle, S., Fuchs, U., Digel, P., Hermann, T., and Battaglia, J.-L.: Analysing Inverse Heat Conduction Problems by the Analysis of the System Impulse Response, Inverse Probl. Sci. En., 22, 297308, doi:10.1080/17415977.2013.780170, 2013.

McConkey, J. W., Malone, C. P., Johnson, P. V., Winstead, C., McKoy, V., and Kanik, I.: Electron impact dissociation of oxygen-containing molecules - A critical review, Physics Reports, 466, 1-103, doi:10.1016/j.physrep.2008.05.001, 2008.

Mlynczak, M. G.: Energetics of the Middle Atmosphere: Theory and Observation Requirements, Adv. Space Res., 17, 117-126, doi:10.1016/0273-1177(95)00739-2, 1996.

Munz, C.-D.: Coupled Particle-In-Cell and Direct Simulation Monte Carlo method for simulating reactive plasma flows, C. R. Mécanique, 342, 662-670, doi:10.1016/j.crme.2014.07.005, 2014.

Normand, F., Granier, A., Leprince, P., Marec, J., Shi, M. K., and Clouet, F.: Polymer Treatment in the Flowing Afterglow of an Oxygen Microwave Discharge: Active Species Profile Concentrations and Kinetics of the Functionalization, Plasma Chem. Plasma P., 15, 173-198, 1995.

Offermann, D. and Drescher, A.: Atomic oxygen densities in the lower thermosphere as derived from in situ 5577-A night airglow and mass spectrometer measurements, J. Geophys. Res., 78, 6690-6700, doi:10.1029/JA078i028p06690, 1973.

Offermann, D., Friedrich, V., Ross, P., and von Zahn, U.: Neutral Gas Composition Measurements between 80 and $120 \mathrm{~km}$, Planet. Space Sci., 29, 747-764, doi:10.1016/0032-0633(81)90046-5, 1981.

Oldham, K. B. and Myland, J. C.: Fundamentals of Electrochemical Science, Academic Press, San Diego, 496 pp., 1994.

Osborne, J. J., Harris, I. L., Roberts, G. T., and Chambers, A. R.: Satellite and rocket-borne atomic oxygen sensor techniques, Rev. Sci. Instrum., 72, 4025-4041, doi:10.1063/1.1406928, 2001.
Park, J. H. and Blumenthal, R. N.: Electronic Transport in 8 Mole Percent Y2O3-ZrO2, J. Electrochem. Soc., 136, 2867-2876, doi:10.1149/1.2096302, 1989.

Perov, S. P. and Rakhmanov, A. S.: Atomic Oxygen Concentration Measurements by a Rocket Near the Mesopause, in: Space Research XVII, vol. 17, 261-264, 1977.

Pireaux, J. J., Chtaïb, M., Delrue, J. P., Thiry, P. A., Liehr, M., and Caudano, R.: Electron spectroscopic characterization of oxygen adsorption on gold surfaces: I. Substrate impurity effects on molecular oxygen adsorption in ultra high vacuum, Surf. Sci., 141, 211-220, doi:10.1016/0039-6028(84)90206-1, 1984.

Pulpytel, J., Arefi-Khonsari, F., and Morscheidt, W.: Threshold ionization mass spectrometry study of singlet molecular oxygen in the deposition of $\mathrm{SnO}_{2}$ by PACVD, J. Phys. D, 38, 1390-1395, doi:10.1088/0022-3727/38/9/010, 2005.

Rapp, M., Gumbel, J., and Lübken, F.-J.: Absolute density measurements in the middle atmosphere, Ann. Geophys., 19, 571-580, doi:10.5194/angeo-19-571-2001, 2001.

Reddy, M. R.: Effect of low earth orbit atomic oxygen on spacecraft materials, J. Mater. Sci., 30, 281-307, doi:10.1007/BF00354389, 1995.

Saliba, N., Parker, D. H., and Koel, B. E.: Adsorption of oxygen on $\mathrm{Au}(111)$ by exposure to ozone, Surf. Sci., 410, 470-482, 1998.

Schmiel, T.: Entwicklung, Weltraumqualifikation und erste Ergebnisse eines Sensorinstruments zur Messung von atomarem Sauerstoff im niedrigen Erdorbit, PhD thesis, Universität Dresden, 154 pp., 2009.

Schrempp, C.: Direct Measurement of Oxygen during a Ballistic Flight on a Sounding Rocket, in: 19th Advanced Measurement and Ground Testing Technology, AIAA-96-2231, doi:10.2514/6.1996-2231, 1996.

Schwandt, C. and Weppner, W.: Kinetics of Oxygen PlatinumStabilized Zirconia and Gold-Stabilized Zirconia Electrodes under Equilibrium Conditions, J. Electrochem. Soc., 144, 37283738, doi:10.1149/1.1838083, 1997.

Singh, H., Coburn, J. W., and Graves, D. B.: Appearance potential mass spectrometry: Discrimination of dissociative ionization products, J. Vac. Sci. Technol. A, 18, 299-305, doi:10.1116/1.582183, 2000.

Thomas, R. and Young, R. A.: Measurement of atomic oxygen and related airglows in the lower thermosphere, J. Geophys. Res.: Oceans, 86, 7389-7393, doi:10.1029/JC086iC08p07389, 1981. 